\title{
Policing the pandemic: crisis without boundaries
}

\section{Robert Broadhurst ${ }^{1}$ OBE QPM}

The police service in the UK is well versed at dealing with major incidents and, less frequently, crises. For the most part these incidents are bounded by both space and time; that is to say they are usually geographically limited and brought under control within hours, or at least days. The most widespread and longest in duration tend to be natural occurrences, such as flooding. The primary role of police in managing major incidents is the preservation of life, the maintenance of order and the prevention of crime. They also take the lead in the coordination of efforts of other emergency services and local partner agencies.

To achieve this, they must have legitimacy and act in a way that engenders trust and confidence, both in their masters and the public they serve, allowing them to continue policing by consent. In a crisis, two of the most important factors are urgency and clear and consistent communication. The police need to channel activity in a way that gives grip and control over the situation, which is often dynamic and fast moving. To do this, they adopt a set of policies and procedures that together constitute a plan, which becomes the framework within which they operate. It is not sufficient, however, for senior officers alone to have a plan; the plan must be shared and understood at every level so that everyone knows their role and what needs to be done. This requires training, practice and experience. Fortunately, major incidents are not frequent, so experience is hard to come by, which is why the police often rely on their pool of public order officers who are regularly used; public order sharing many of the key components of crisis management.

The current pandemic is beyond the experience of any police officer in the UK and does not fit easily into the commonly used definitions of major incident or crisis. Indeed, there are some who say it should be regarded as a "wicked problem" characterised by multiple centres, lack of information, rapidly degrading conditions and inability to prioritise, creating an apparent "no win" situation (Rittel and Webber, 1973). Despite a pandemic being near the top of the UK risk register for many years, successive governments have balked at taking any meaningful action, so when COVID-19 did appear in early 2020, little planning or preparation had taken place. In the risk assessment for the 2012 London Olympics, the potential for a pandemic was discounted, as it would have resulted in the cancellation of all games activities and so did not require any planning activity. Not only was this new threat outside the experience of the police, it did not appear to have the usual boundaries they are used to operating within. There was a very real danger that their actions would lack legitimacy, especially those that appeared to contradict their core values, such as the freedom of movement. The only way out of this was for the police to adopt major incident principles and innovate where necessary.

They adopted a command structure based on the three levels of strategic, tactical and operational delivery. At the strategic level there is one senior officer in charge, the Gold commander; Gold will set the strategy and give overall direction. Silver is the tactical lead and will set out the method by which the strategy will be achieved. Control and consistency is best maintained by having one Silver commander, but geographically spread incidents may be better suited to multiple Silvers. Deployment and operational activity is the responsibility of Bronze commanders, of which there could be any number; they will either have a geographic responsibility or a functional one based on a specialism. This command structure gives clarity to all staff as to who is doing what role, what is expected of them and how it is to be delivered; it aids fast decision making and is transparent and accountable. 
Vol. 8, No. 1, 136-138.

The Gold commander sets a strategy for the operation; a clear aim supported by objectives and underpinned by rationale. This becomes a "Golden thread" running through all the tactical and deployment plans. No action should be taken that does not deliver the requirements of the strategy. In setting the strategy, Gold can use a number of tools, the most useful of which is SDI - Scale-Duration-Impact. At the start of 2020, the scale may have been assessed as confined to a few urban areas, the duration measured in months and the impact minimal. By the end of 2020, the SDI had become global, measured in years and with an impact on society not seen outside of war. The strategy is a living document and should be reviewed regularly, adapting to the changing landscape so as to always be fit for purpose.

At the tactical level, Silver will not only have to set plans for implementing and enforcing new laws and guidance relating to the pandemic, but will also have to introduce safe working practices for daily policing activities. At this time of change and heightened demand the workforce will have been reduced, as officers and staff either contract COVID19 themselves, have to self-isolate or stay at home as carers or parents. Strategy and tactics play out at the operational level where the legitimacy of police action is tested most and, again, the flexibility of the plan has allowed the approach to change to fit the prevailing circumstances. For a long time, in keeping with the principles of policing by consent, they adopted the four E's - Engage-Explain-Encourage-Enforce - and appeared reluctant to issue COVID-19 fines. Even this measured approach brought them into conflict with a public who saw this as encroaching on their rights of freedom of movement and association, especially with family and friends. Almost a year later, the police are being much more assertive in their enforcement of COVID-19 laws, with fines doubling over winter to over 350 a day in January 2021 as small but regular groups of society openly break the rules.

A commonly used decision-making model has long been a mainstay of crisis management and has been adopted across a range of policing disciplines. Understood by everyone involved, it brings consistency to the process and ensures that all relevant information is considered before decisions are made. Command team members find it a useful tool during the planning, execution and post-event stages of an incident. The model always begins with information and intelligence, which should drive all activity; as intelligence changes, so the model should be re-run to ensure actions are suited to need. Following this, a risk assessment allows commanders to plan for the safest form of activity. In the pandemic, risk assessment is driven by scientists and police have to follow their lead; unfortunately, scientists do not always agree on the best course of action and some of their proposals are not easily translated into police action. Police action is constrained by law and internal policy, and these have to be considered next. During the pandemic, new laws have been introduced at an alarming rate and the police have had to adopt them with little or no time to train offices and prepare them. There has also been a plethora of guidance and best practice, with unclear boundaries between guidance and legislation. Having analysed the intelligence, assessed the risk and considered the current legislation, only then can the command team develop actions, prepare contingencies, brief their staff and put the plan into action. Once underway, the plan should be regularly reviewed and, if necessary, adapted to cater for changes in intelligence, risk or, in this current situation, changes in legislation. Crucially, all decisions should be contemporaneously recorded - a discipline that is vital should decisions ever be challenged.

The final aspect of the process to be considered here is the debrief - a central pillar of the crisis management model. Regular debriefs, in a non-judgemental environment, allow officers to consider what went well, what could have been done better and what needs to change in the future. In the fullness of time this can lead to changes in policy, training or equipment, but, in the short term, it allows for actions to be improved to keep the public and the police safer and to prevent the same mistakes happening again. It is inevitable that at some stage the police will be asked to account for their handling of the pandemic, either in the courts or a formal enquiry, or both. By following the model, they will be able to defend 
their actions. There are no right or wrong decisions in a crisis, only good and bad outcomes. Commanders will be able to justify that the actions they took were based on the intelligence and prevailing conditions at the time they were made.

The pandemic is unprecedented, although not entirely unexpected. In countering it, the government have taken actions that would normally be unacceptable in a liberal, democratic society. The police have borne, and continue to bear, the brunt of enforcing government policy and, in doing so, have managed to maintain the legitimacy of policing by consent. They have done this by adopting the principles and models of crisis management and working to a plan that is proportionate, lawful, necessary and accountable.

\section{Note}

${ }^{1}$ Robert Broadhurst served for 36 years in the Metropolitan Police, London, from 1977 to 2013 . He lectures for the Emergency Planning College, is an Associate with the College of Policing and delivers on the Indian Police Service Mid-Career Programme on mega-event policing. bossnest@yahoo.com

\section{Reference}

Rittel, H., \& Webber, M. (1973) "Dilemmas in a General Theory of Planning." Policy Sciences, 4(2), 155-169. Available at: http://files.meetup.com/11447962/Rittel\%2BWebber_1973_Policy Sciences4-2.pdf [Accessed: 28 January 2021]. 